\title{
Breves apontamentos para uma crítica marxista do poder judiciário
}

Pablo Biondi*

Resumo: O presente artigo faz uma breve análise do Poder Judiciário sob um ponto de vista marxista, i.e., considerando-o como uma parte de um aparato de Estado cujo propósito é reproduzir as relações burguesas de produção numa dada sociedade. Neste esforço teórico, é importanteenfrentaralgumasconcepçõesreformistascontemporâneas que sugerem os tribunais como um promissor campo de batalha, defendendo a possibilidade de mudanças sociais substanciais pelas mãos de advogados, promotores e juízes progressistas ou de esquerda. Contra estas honestas (mas ingênuas) crenças, o marxismo opõe determinações estruturais e o jogo das maquinarias do Estado, sobretudo os papéis repressivos e ideológicos desempenhados pelo Judiciário, destacando que todos estes elementos prevalecem sobre ações individuais (ainda que combativas).

Palavras-chave: marxismo, direito, Judiciário.

Abstract: The current paper makes a brief analysis of Judicial Power from a marxist standpoint, i. e., by considering it as a part of an state apparatus whose purpose is to reproduce the bourgeois relations of production in a given society. In this theoretical effort, it is important to face some contemporaneous reformist conceptions which suggest courts as a promising battlefield, defending the possibility of substantial social changes by the hands of progressive or left-wing lawyers, persecutors and judges. Against these honest (but naive) creeds, marxism opposes structural determinations and the game of machineries of state, overall the repressive and ideological roles

* Advogado e doutorando em Direitos Humanos pela USP. E-mail: pablobiondi@ gmail.com.

caderno cemarx, no $7-2014 \quad 139$ 
played by the Judiciary, featuring that all these elements prevail over individual (even combative) actions.

Keywords: marxism, Law, Judiciary.

\section{Introdução}

No presente ensaio, nosso propósito é estudar criticamente uma das bases materiais e ao mesmo tempo ideológicas do direito: o Poder Judiciário. Situaremos esta instituição jurídica nos marcos da teoria marxista do direito e do Estado, o que permitirá a compreensão de como se exercem os papéis coercitivos e ideológicos da Justiça mesmo que a partir de alguns breves apontamentos.

Percorrendo os desdobramentos da localização estrutural do Judiciário, seremos conduzidos pela indagação quanto às possibilidades de emancipação e transformação que estariam ou não contidas neste aparato. Trata-se de uma indagação que está presente na consciência de todos os juristas progressistas, que abraçam posições de esquerda ou pelo menos à esquerda do senso comum de seu meio.

A maioria destes progressistas, muito honestos em suas aspirações, respondem afirmativamente à questão sem maiores reflexões. Alguns acabam atribuindo soberba importância a si mesmos, como se as maiores agruras sociais pudessem ser superadas pela somatória de suas atuações individuais como profissionais do direito. Outros, mais comedidos, denunciam o direito como instrumento de controle social e de manutenção de privilégios para, no instante seguinte, buscar "rachaduras", "brechas", "contradições", enfim, diferentes tipos de atalhos que pudessem redimir o direito, convertendo-lhe em ferramenta de luta, transformação e, quiçá, emancipação social.

Veremos como a teoria marxista, concebendo o Judiciário centralmente como um aparato de Estado atrelado à reprodução econômica e social, desmistifica as ilusões nutridas por aqueles que não conseguem ultrapassar os horizontes da ideologia burguesa.

140 Breves apontamentos para uma crítica marxista do poder judiciário 


\section{O Judiciário como garante das relações jurídicas}

Nossa análise marxista parte de Eugeny Pasukanis, o autor que, conforme nos parece, melhor compreendeu o direito, e isto na medida em que manejou as categorias da dialética de Marx com notável habilidade.

Para Pasukanis, o direito não é um conjunto de normas sem vida, e sim uma cadeia ininterrupta e dinâmica de relações travadas por sujeitos de direito. Estes sujeitos, por sua vez, não são definidos por disposições normativas da ordem jurídica. Eles são abstraídos da prática concreta dos indivíduos na constituição de sua vida em sociedade, trazendo consigo a marca de ferro à brasa da mercadoria, conforme a tendência totalizante (e totalitária) do capitalismo.

Seguindo a metodologia marxiana, que capta os fenômenos num movimento teórico que vai da forma mais simples a mais complexa, do abstrato ao concreto pensado, o jurista soviético explica que "o sujeito éoátomo da teoriajurídica, seu elementomaissimples, indecomponível" (1989, p. 81), assim como a mercadoria é a categoria mais elementar da sociedade capitalista. É na categoria sujeito de direito que se encontra a especificidade do direito, e não na força coercitiva das normas jurídicas, como pretendem os positivistas e afins.

O sujeito jurídico é oriundo das relações de produção que assim o engendram. Ele se situa na esfera das superestruturas, o que significa que, por ser um componente do mundo jurídico, sua autonomia ontológica é muito limitada, predominando seu caráter epifenomênico. O direito, tal como o Estado, não tem vida própria e somente pode ser compreendido no conjunto das relações de produção, que nada mais é do que a estrutura da sociedade ${ }^{1}$.

\footnotetext{
${ }^{1}$ Nos dizeres de Marx, "as relações jurídicas, bem como as formas do Estado, não podem ser explicadas por si mesmas, nem pela chamada evolução geral do espírito humano; (...) Na produção social da própria existência, os homens entram em relações determinadas, necessárias, independentes de sua vontade; essas relações de produção correspondem a um grau determinado de desenvolvimento de suas forças produtivas
} 
Pasukanis encontra na produção e na circulação mercantil o suporte estrutural do sujeito jurídico. $\mathrm{O}$ ato de troca é a base material pela qual os indivíduos produzem sua existência no modo de produção capitalista, e é somente com o capitalismo que ele se generaliza. A partir do instante em que se instauraram as condições objetivas que ensejaram a sociedade burguesa (quais sejam: concentração de meios de produção e dinheiro nas mãos de uma classe proprietária, de um lado; de outro, a posse exclusiva da própria força de trabalho para a massa da população), as atividades econômicas necessariamente passariam por um momento mercantil. A manutenção dos fatores de produção (inclusive da mão-de-obra) passou a se efetivar pela aquisição de bens no mercado, tendo-se como novidade a emergência de um mercado da força de trabalho.

$\mathrm{Na}$ circulação, o homem se despe de suas concretudes, assumindo as vestes de um "proprietário abstrato e transposto para as nuvens". O autor soviético afirma que, neste cenário, "cada homem torna-se um homem em geral, cada trabalho torna-se trabalho social útil em geral, cada indivíduo torna-se um sujeito de direito abstrato (1989, p. 94)". E assim é porque, ao alienar ou comprar um produto, o homem é formalmente livre e igual ao outro contratante. Ademais, a liberdade e a igualdade jurídicas só encontram sua razão de ser em torno da propriedade privada, o sustentáculo da santíssima trindade que compõe o sujeito de direito. Como diz Bernard Edelman (2001, p. 110), "A colocação em movimento da propriedade privada cria de fato uma liberdade e uma igualdade, mas esta liberdade e esta igualdade são aquelas mesmas da propriedade privada"2 .

materiais. A totalidade dessas relações de produção constitui a estrutura econômica da sociedade, a base real sobre a qual se eleva uma superestrutura jurídica e política e à qual correspondem formas sociais determinadas de consciência. O modo de produção da vida material condiciona o processo de vida social, política e intelectual" (2008a, p. 45).

${ }^{2}$ Tradução nossa.

142 Breves apontamentos para uma crítica marxista do poder judiciário 
Na perspectiva do direito, portanto, o que se tem é o encontro entre dois proprietários de mercadorias diversas, em nada importando as classes a que pertencem os contratantes no mundo real. Eis aí o mecanismo (jurídico, frise-se) que encobre a extração da mais-valia com "verdadeiro paraíso dos direitos inatos do homem", pois, como registrou Marx (2008b, p. 206), "só reinam aí liberdade, igualdade, propriedade e Bentham".

E é como corolário destas categorias jurídicas emanadas do mercado que se consagra o Poder Judiciário. Afinal, se os sujeitos são livres e iguais entre si, então um não pode se impor ao outro pela força em caso de conflito. É preciso que uma autoridade pretensamente equidistante se coloque entre as partes para que se decida sobre os direitos de cada uma delas, tutelando as relações de caráter mercantil e as que delas são derivadas ou que se espelham nelas de alguma forma (como o casamento, apenas a título ilustrativo).

Ora, ao garantir a circulação mercantil, o Judiciário coloca-se como garante geral do capitalismo, pois a produção capitalista não só se realiza mediante uma troca de mercadorias (qual seja, força de trabalho por salário), como também pressupõe um mercado constituído e operacional. Ao considerarmos que a exploração das classes dominadas e a reprodução social, no capitalismo, mediatizamse por esta relação mercantil, podemos concluir com Joachim Hirsch (1977, p. 88) que "numa formação social capitalista é preciso que a exploração e a reprodução das classes não se efetuem (...) diretamente pela utilização física da violência, mas através da própria reprodução das relações de produção, regida pela lei do valor". Consequentemente, há uma separação do aparelho de coerção física em face da classe dominante, a qual se coloca na relação com a classe dominada como um conjunto de contratantes dispostos a trocar valores equivalentes com os trabalhadores que contratam. A Justiça, então, nada mais é do que uma das máscaras utilizadas pelo Estado burguês na sua interpretação do papel de ente público, contemplando a sociedade civil como um oceano de indivíduos que se nivelam apenas sob as lentes jurídicas. 
Está posta, enfim, a fórmula do Estado propriamente capitalista, o fecho do esquema jurídico na maturidade das trocas mercantis.

Note-se que este mecanismo de processamento de conflitos é muito peculiar ao capitalismo, bem como a maneira de o Estado atuar. Se o Estado é, em todas as épocas, violência de classe concentrada, daí não se infere que esta violência é exercida do mesmo modo na história, e a emergência de um Judiciário moderno e organizado sob o modo de produção capitalista só pode ser compreendida nesses marcos.

\section{O Judiciário como aparelho repressivo de Estado}

É cediço que o Estado constitui um conjunto de aparelhos que, orientados para a reposição sistêmica, exercem funções repressivas (exército, polícia, tribunais etc.) e ideológicas (escola, mídia, igreja etc.). Althusser, por exemplo, estabelece uma divisão entre aparelhos repressivos de Estado e aparelhos ideológicos de Estado, sendo que, nos primeiros, predomina o uso da coerção, ao passo que nos segundos predomina a cooptação ${ }^{3}$.

O Estado capitalista, em seu aspecto repressivo, caracterizase por deter o monopólio do uso da força bruta, quer dizer, por ser a única entidade legítima para aplicar as formas mais contundentes de coerção. Na sociedade feudal, por exemplo, a situação era outra: o feudo era uma unidade política autônoma, sendo que cabia ao senhor exercer a violência. Como vimos, esta diferença decorre do caráter mercantil da sociedade capitalista, ou seja, da generalização das trocas que impõe a igualdade jurídica entre os indivíduos.

Daí se tem que o Estado capitalista, em condições de normalidade, reporta-se não a súditos ordinários, e sim a sujeitos de direito.

\footnotetext{
${ }^{3} \mathrm{O}$ aparelho jurídico, em particular, seria ao mesmo tempo repressivo e ideológico, segundo Althusser (2007, p. 68). A teoria de Edelman (2001, p. 104) faz um raciocínio análogo para o direito, inferindo que "o direito assume esta dupla função de fixar concreta e imaginariamente - e seria melhor dizer que a fixação concreta jurídica é ao mesmo tempo ideológica - o conjunto das relações sociais".
}

\begin{tabular}{l|l}
144 & Breves apontamentos para uma crítica marxista do poder judiciário
\end{tabular} 
A sociedade burguesa apresenta-se como uma cadeia ininterrupta de relações jurídicas entre sujeitos, sendo que o aparato estatal reflete, no seu funcionamento, esta estrutura. Politicamente, entra em cena a figura do cidadão, uma entidade que possui direitos em face do Estado e que pode, por intermédio do Judiciário, submetê-lo a uma demanda.

Fazendo-se o caminho oposto, percebe-se que o Estado, a seu turno, deve coagir os indivíduos enquanto cidadãos. Isto se concretiza na maneira pela qual ele exerce a violência (ao menos em tese), que pressupõe a observância aos direitos civis e políticos que constituem a entidade jurídica chamada cidadão. Eis porque o Estado capitalista, normalmente ${ }^{4}$, exerce a força bruta a partir de procedimentos burocráticos e jurídicos.

Qualquer limitação à liberdade (no uso de força policial em tumultos, controle de fronteiras, fiscalizações em geral etc.), e à propriedade (na cobrança de tributos, tombamento, desapropriação etc.), em princípio, só pode ocorrer com as reservas previstas nas chamadas garantias fundamentais. E no caso de excesso, de uso abusivo e desmedido da coerção, o Estado pode ser submetido à jurisdição.

Para que se perceba esta característica, é proveitoso analisar o direito penal. A supressão concreta, para um indivíduo, do desfrute de seus direitos é condicionada por um mandado de prisão, expedido por um juízo competente que permita o desenvolvimento de uma lide. O direito processual penal não deixa dúvidas. Nele, o Estado é cindido em personalidades distintas: Poder Judiciário e Ministério Público. O primeiro personifica o Estado-juiz, o poder público encarregado de apreciar os conflitos entre os átomos da sociedade, ao passo que

\footnotetext{
${ }^{4}$ Assumimos aqui que a forma normal do Estado burguês é o Estado de direito, a conformação institucional do regime democrático-liberal. O autoritarismo cru e desmedido das ditaduras corresponde a um estágio da luta de classes em que o regime democrático já não é capaz de cumprir com suas tarefas de reprodução da ordem existente.
} 
o segundo personifica a própria sociedade, que demanda contra um indivíduo acusado de atentar contra ela.

Enquanto a autoridade feudal, para se voltar ao exemplo anterior, não adotava nenhum regramento específico para oprimir e coagir as pessoas, a autoridade burguesa desempenha estes expedientes com respaldo em medidas administrativas e, na maioria das vezes, judiciais, perfazendo o devido processo legal. O servo da gleba, ao contrário do operário atual, não tinha a garantia jurídica de ser agredido pelo poder político mediante ordem judicial, e nem podia utilizar um habeas corpus para se defender. Faltava-lhe o status de sujeito de direito.

E mais: se o servo estava imediatamente submetido ao despotismo de seu explorador, o mesmo não se aplica ao operário. O poder diretivo do empregador (que abrange um poder punitivo) é adstrito ao contrato de trabalho. O máximo que o capitalista pode fazer contra o trabalhador, diretamente, é dispensá-lo por justa causa.

Se quiser realizar um ato de repressão propriamente dito, não poderá usar uma força militar privada. Ser-lhe-á necessário mover uma ação para que um órgão judicial, racionalizando o monopólio da violência, utilize-o contra os trabalhadores, como na hipótese de uma ordem judicial que determine a desapropriação forçada de uma fábrica ocupada. É o que se tem numa sociedade em que a extração do excedente de trabalho se opera economicamente, isto é, passando pela troca, e não pelo mando direto, como no feudalismo ou na escravatura. A exploração pré-capitalista é realizada por um ato de poder político (a subjugação física e armada), e não simplesmente tutelada por uma autoridade.

Observe-se que a adstrição a procedimentos é um princípio igualmente consagrado na Administração. Outrossim, nela se verifica uma clara distinção entre o público e o privado, bem como uma distinção entre a figura do Estado e seus gestores. Ainda assim, é no Poder Judiciário que esta lógica é finalmente conduzida ao seu paroxismo. Nele, "o Estado eleva-se, em certo sentido, para além de si mesmo",

146 Breves apontamentos para uma crítica marxista do poder judiciário 
como afirmou Karl Liebknecht (2002, p. 23), pois nele “o próprio Estado - e, na verdade, também seu Poder Legislativo - submete-se a esse Poder [Judiciário], criado por ele mesmo", regulamentando juridicamente o funcionamento dos aparelhos estatais em seu conjunto.

Cumpre ressaltar que este modus operandi do Estado burguês, mais do que espelhar a estrutura econômica, opera imediatamente para beneficiá-la. Os expedientes de controle e ritualização do uso da força bruta pelo aparelho estatal, que encontra no Judiciário seu principal instrumento, com todos os seus trâmites burocráticos e sua dinâmica jurisprudencial, faz da violência estatal um conjunto de eventos calculáveis, previsíveis. E a previsibilidade do agir estatal éum benefício do qual o mercado não pode prescindir. Seja para investir capital ou simplesmente para ofertar as mercadorias produzidas, os capitalistas precisam de condições mínimas para estimar o comportamento do Estado no jogo econômico, ou melhor, para medir o alcance exato da intervenção estatal na esfera privada (os limites da concorrência, o alcance das normas de segurança no trabalho, a extensão dos direitos dos consumidores etc.). O que vale e o que não vale deve estar claro, e apenas a Justiça (particularmente os tribunais superiores) pode pacificar a interpretação sobre as normas jurídicas. Não basta que a lei seja aplicável a todos indistintamente; é preciso que seus intérpretes oficiais assegurem que elas sejam interpretadas e aplicadas indistinta e regularmente - daí a importância da jurisprudência, o entendimento consolidado dos tribunais.

Neste sentido, o Judiciário coloca-se não apenas como um agente da repressão, mas também como o agente (o único legítimo para tanto) da medida da repressão, a instância encarregada de aferir o quantum de intervenção estatal na esfera dos particulares é cabível. E no tocante à violência do Estado, isto é muito claro: o direito penal, exemplificativamente, é a dosimetria do poder punitivo do Estado contra os cidadãos, e nada além disso. Pode-se dizer que se trata de uma forma social mais civilizada do que os tribunais da Santa 
Inquisição, de fato; entretanto, sua essência está na força bruta e na sua base capitalista, e não na dignidade humana ou no avanço do espírito ético. O Poder Judiciário é, antes de tudo, uma instituição inserida num modo de produção espoliativo.

\section{O Judiciário como aparelho ideológico de Estado}

O Judiciário, conforme estudamos, é o fecho das relações jurídicas entre os sujeitos de direito, colocando-se como garante dessas relações e como instância decisória de conflitos entre indivíduos juridicamente nivelados (abstraindo-se, principalmente, as classes sociais envolvidas). Desta sua função social e do modo de agir correlato desdobra-se uma ideologia cujo caráter burguês é manifesto, e isto é perceptível até mesmo nos setores progressistas do aparelho judicial.

Tomemos, por exemplo, a Associação Juízes para a Democracia (AJD) - talvez o que haja de melhor no Judiciário brasileiro. Em que pese o mérito desta organização em questões atinentes às lutas sociais, fato é que todos os seus posicionamentos são embasados por uma apologia ao Estado e ao regime burguês, o que se constata no artigo 2.. de seu estatuto ${ }^{5}$, que já de início coloca como finalidade da Associação "o respeito absoluto e incondicional aos valores jurídicos próprios do Estado Democrático de Direito".

Além disso, indica-se ainda "a promoção da conscientização crescente da função judicante como proteção efetiva dos direitos do Homem, individual e coletivamente considerado" , bem como "a consequente [sic] realização substancial, não apenas formal, dos valores, direitos e liberdades do Estado Democrático de Direito". Ou seja: quer-se fazer com que a ordem jurídica seja levada a cabo, e não superada.

Note-se que lutar por liberdades democráticas não é a mesma coisa que defender a democracia burguesa, que assume a forma de

${ }^{5}$ Conferir o texto integral em http://www.ajd.org.br/quem_somos_estatuto.php.

148 Breves apontamentos para uma crítica marxista do poder judiciário 
Estado de Direito. Sob este regime, as liberdades são somente aquelas admissíveis nos marcos da produção mercantil, não se admitindo que as massas possam exercer sua autodeterminação coletiva. É digna de mérito e reconhecimento, assim, a posição da AJD em defesa dos manifestantes das "jornadas de junho" ${ }^{\text {, }}$, mas não se deve esquecer que seu escopo é uma "humanização" do regime, algo muito aquém de um programa socialista.

É por elementos como este que se constata que a Justiça merece o título de aparelho ideológico; ela desempenha atividades de formação ideológica, formando operadores do direito. O Judiciário ventila uma concepção jurídica de mundo ${ }^{7}$ e forma indivíduos nos marcos da ideologia burguesa, e disto nem os juristas mais progressistas conseguem escapar, conforme verificamos. O humanismo da ideologia jurídica pode estar mais à esquerda ou mais à direita, mas segue sendo burguês ${ }^{8}$. Quanto aos conservadores, estão perfeitamente acomodados com o status quo e com a justeza das relações sociais tuteladas pelo direito e por isso não trataremos deles. Para estas pessoas, o direito apenas sedimenta uma concepção ideológica já estabelecida ou, o que é ainda mais comum, adorna um interesse de classe com um discurso pretensamente civilizado. O que preocupa mais, de fato, é o efeito das instituições jurídicas sobre os juristas insatisfeitos com as mazelas do capitalismo.

${ }^{6}$ http://www.ajd.org.br/arquivos/publicacao/80_jornal-60.pdf.

${ }^{7}$ Engels e Kautsky (1991, p. 24-25) perceberam que esta concepção, própria da burguesia e da sociedade forjada à sua imagem e semelhança, introduziu a seguinte mudança com relação ao período medieval: "O dogma e o direito divino eram substituídos pelo direito humano, e a Igreja, pelo estado. As relações econômicas e sociais, anteriormente representadas como criações do dogma e da Igreja, porque esta as sancionava, agora se representam fundadas no direito e criadas pelo estado".

${ }^{8}$ Por que o comunismo não pode se identificar com os "direitos eternos do homem"? Porque esses direitos decorrem das relações de produção e de troca capitalistas; eles fundam a igualdade universal dos sujeitos de direito sob a base do valor de troca, que torna possível a compra e venda da força de trabalho, a exploração burguesa. O humanismo (direitos do homem) encobre, assim, a dominação de classe (NAVES, 2008, p. 58). 
Aqueles que vivem do Poder Judiciário (juízes, promotores, advogados etc.), ao lidarem cotidianamente com mecanismos de poder, são conduzidos à ilusão de que podem transformar a sociedade, se quiserem. O poder decisório do juiz lhe faz crer que verdadeiros prodígios poderiam se realizar pelas ordens judiciais que assina. As prerrogativas de custus legis do Ministério Público leva o procurador a se entender como uma imprescindível força motriz no curso das coisas que passam pelo direito. O advogado, por sua vez, leva a ferro e fogo o enunciado constitucional de que sua profissão é indispensável para os serviços da Justiça (o que se deve ao princípio da inércia do Judiciário). Todos, embora cada um a seu modo, são levados a crer que sua atuação pode mover montanhas, que a máquina judiciária, se devidamente direcionada por seus operadores, poderia revolucionar a sociedade.

Com a juridificação do mundo (inclusive da política, em alguns aspectos), à qual segue a judicialização de tudo, o Poder Judiciário aparece como um canto de sereia para os que são do ramo. Afinal, pela Justiça, parece que tudo é possível: destituir governantes, conceder benefícios sociais sonegados pela administração pública, sancionar empresas que poluem o meio ambiente e atacam a liberdade sindical etc.

Todavia, o jurista que assim crê não se dá conta de que o papel de uma superestrutura na sociedade está muito além do querer de cada agente individual. Instituições como o Judiciário não são como um clube formado por amigos do bairro que podem decidir sobre seus rumos como bem lhes aprouver. Em se tratando de instituições de Estado, deve-se perceber que sua origem está conectada com a reprodução do sistema social, ou seja, com um conjunto de relações sociais que estão para além do domínio das vontades individuais. Contra as relações capitalistas de produção, a única força capaz de se impor com eficácia advém não das instituições criadas para lhes proteger (como é o caso do Judiciário), mas sim de sua perpétua negação, qual seja, a classe trabalhadora explorada.

150 Breves apontamentos para uma crítica marxista do poder judiciário 


\section{A transformação social pode vir pela via judiciária?}

Considerando-se a localização do Judiciário no modo de produção capitalista, evidencia-se que o sistema confia a este aparelho funções sem as quais não pode subsistir. A estrutura social exige um aparato nos moldes em que a Justiça se apresenta, constituindo seus caracteres mais íntimos. Nesta ordem de considerações, não se pode esperar que um dos aparelhos de Estado do capitalismo seja utilizado para subverter sua finalidade estruturalmente estabelecida, nem que um aparelho funcione independentemente dos outros.

Quando se concebe a Justiça como aparelho de Estado, há de se entendê-la como uma instituição que, agindo a sua maneira, funciona em conjunto com outras que, cada qual a seu modo, concorrem para o mesmo fim: a reprodução das relações de produção existentes. A proeminência de uma ou de outra está condicionada ao regime fixado. Na democracia burguesa, despontam como instituições centrais o Parlamento, o Executivo e o Poder Judiciário9. Nos regimes autocráticos da burguesia, em contraste, ganham força a Polícia e o Exército. A história demonstra que a falência de um aparelho em suas atividades de dominação abre caminho para a ascensão de outro, o que geralmente se configura como endurecimento político da autoridade - uma reorganização dos aparelhos destinada a conservar as relações de produção. Eis porque, para o marxismo clássico, a questão que se coloca é a destruição do Estado burguês, e não a ocupação paulatina de seus espaços.

Contudo, cabe a ressalva de que o uso do espaço judiciário em si não é sintoma de capitulação ao reformismo, pois o enfrentamento

\footnotetext{
${ }^{9}$ O Judiciário goza da vantagem de ser menos suscetível a pressões populares e sofrer menos com ônus políticos, já que seus cargos não são eletivos. E embora haja eleições para juízes em alguns países, como ocorre nos EUA, esta é a exceção, jamais a regra. E mesmo nos Estados Unidos, os membros da Suprema Corte não são eleitos, e sim indicados pela presidência da República. Vale notar que, para o regime e para os governantes, é sempre mais confortável atacar os trabalhadores pelo Judiciário, servindo-se do asséptico pretexto de se cumprir uma ordem judicial.
} 
econômico e político ensejam questões práticas em que algumas medidas judiciais, dependendo do caso, podem ser úteis. Estaríamos diante do cúmulo do romantismo da clandestinidade se uma organização se recusasse a impetrar um habeas corpus em favor de um militante preso, ou a contestar judicialmente uma ação possessória que tenha por objeto a expulsão de trabalhadores que ocuparam um terreno. No entanto, é importante entender que, nesses casos, mesmo que, ao final, a Justiça acolhesse o interesse dos trabalhadores, nem por isso o aparato judicial estaria sendo redentor. Tratar-se-ia de uma vitória (a ser vivamente comemorada, inclusive), mas de uma vitória localizada, inscrita numa luta específica e individualizada no tempo e espaço. A força social de subversão não pode advir do Judiciário, mas somente contra ele, pulsando diretamente da classe trabalhadora nas ruas e praças, e sob um estandarte revolucionário.

\section{Conclusão}

Não é nenhuma novidade, para os marxistas, situar o Judiciário como um aparelho de Estado, é dizer, como um pilar de sustentação da ordem. Entretanto, pareceu-nos oportuno, e até mesmo necessário, esmiuçar o funcionamento deste aparato para reafirmar a crítica marxista do direito e do Estado, haja vista o fato de que o socialismo foi declarado como uma peça de museu após a derrocada da URSS (que sequer era socialista, diga-se logo), levando a maior parte da esquerda a buscar consolo nas mais diversas vertentes do reformismo. E como a crença no direito e no Judiciário perpassa em maior ou menor medida as propostas de transformação social no interior do capitalismo, consideramos relevante atacar este flanco.

É muito cômodo para o jurista supor que o Judiciário, seu espaço de atuação por excelência, seja um caminho aberto e convidativo para a emancipação social. Este cenário idílico, entretanto, não consegue se manter numa leitura marxista da realidade, que identifica as determinações econômicas dos fenômenos e levanta o véu da ideologia.

152 Breves apontamentos para uma crítica marxista do poder judiciário 
O jurista progressista, ao conceber o Judiciário como uma arena em disputa, e que pudesse ser impunemente dirigida por quaisquer intenções, coloca-se como a mão esquerda de uma máquina opressora, não obstante suas nobres intenções. Não pode um indivíduo, por sua mera vontade, superar o peso da superestrutura em que se insere, muito menos atuar nela como se fosse possível, a partir desta localização, combater a estrutura social. A arrogante pretensão de alguns juristas progressistas quando enaltecem sua própria atuação é infundada, e jamais poderá substituir as massas em sua ação revolucionária. A emancipação dos trabalhadores só pode se dar por obra dos próprios trabalhadores; e não pelo Estado burguês, mas contra ele.

E esperamos ter demonstrado, além disso, que a ideologia burguesa atua não só pelas mãos dos juristas conservadores e reacionários, mas também - e principalmente - pelos operadores progressistas do direito, que enxergam no Judiciárioum espaço propício para a transformação social. Ao fazê-lo, pagam um importante tributo ao capitalismo na esfera da ideologia. É óbvio que eles são preferíveis aos conservadores e reacionários, o que não quer dizer que estejam infensos à lógica burguesa do direito.

Por fim, é justo pontuar que a crítica marxista, amparada no rigor metodológico de Marx, não vem para deslegitimar o esforço dos promotores que se ocupam de fiscalizar as relações de trabalho, dos advogados que cerram fileiras junto aos movimentos sociais ou dos juízes que balizam seus entendimentos pela doutrina dos direitos humanos. No entanto, ela vem para identificar o papel do direito no conjunto das relações sociais, com suas contingências e determinações. Neste percurso, nada pode ser poupado. Quem opta pelo marxismo precisa estar pronto para encarar as instituições jurídicas na sua crueza, compreendendo suas limitações e suas características mais intrínsecas. 


\section{Bibliografia}

ALTHUSSER, Louis. Aparelhos ideológicos de Estado - nota sobre os aparelhos ideológicos de Estado. Tradução de Walter José Evangelista e Maria Laura Viveiros de Castro. São Paulo: Graal, 2007.

EDELMAN, Bernard. Le droit saisi par la photographie -élements pour une théorie marxiste du droit. Paris: Flammarion, 2001.

ENGELS, Friedrich; KAUTSKY, Karl. O socialismo jurídico. 2. ed. Tradução de Lívia Cotrim e Márcio Bilharinho Naves. São Paulo: Ensaio, 1991.

HIRSCH, Joachim. “Observações teóricas sobre o Estado burguês e sua crise". In: POULANTZAS, Nicos (org.). Estado em crise. Tradução de Maria Laura Viveiros de Castro. Rio de Janeiro: Graal, 1977.

LIEBKNECHT, Karl. Acerca da justiça de classe. Tradução de Emil von München. São Paulo: Instituto José Luís e Rosa Sundermann, 2002.

MARX, Karl. Contribuição à crítica da economia política. $2^{a}$. ed. Tradução de Florestan Fernandes. São Paulo: Expressão popular, 2008a.

O capital - crítica da economia política. Livro 1, Vol 1. Trad. Reginaldo Sant'Anna. 26 $6^{\mathrm{a}}$ Ed. Rio de Janeiro: Civilização Brasileira, 2088b.

NAVES, Marcio Bilharinho. Marx: ciência e revolução. São Paulo: Quartier Latin, 2008.

PASUKANIS, Eugeny B. A teoria geral do direito e o marxismo. Tradução de Paulo Bessa. Rio de Janeiro: Renovar, 1989.

154 Breves apontamentos para uma crítica marxista do poder judiciário 